Calculations of electron scattering from cadmium

This content has been downloaded from IOPscience. Please scroll down to see the full text.

2012 J. Phys.: Conf. Ser. 388042026

(http://iopscience.iop.org/1742-6596/388/4/042026)

View the table of contents for this issue, or go to the journal homepage for more

Download details:

IP Address: 130.56.107.193

This content was downloaded on 24/06/2014 at 07:53

Please note that terms and conditions apply. 
XXVII International Conference on Photonic, Electronic and Atomic Collisions (ICPEAC 2011) IOP Publishing Journal of Physics: Conference Series 388 (2012) 042026 doi:10.1088/1742-6596/388/4/042026

\title{
Calculations of electron scattering from cadmium
}

\author{
M.J. Berrington*1, D.V. Fursa*, I. Bray*, R.P. McEachran ${ }^{\dagger}$, and A.D. Stauffer ${ }^{\S}$ \\ ${ }^{*}$ Centre for Antimatter-Matter Studies, Department of Imaging and Applied Physics, Curtin University, \\ Perth, WA 6845, Australia \\ ${ }^{\dagger}$ Centre for Antimatter-Matter Studies, Research School of Physics and Engineering, Australian National \\ University, Canberra, ACT 0200, Australia \\ ${ }^{\S}$ Department of Physics and Astronomy, York University, Toronto, ON M3J 1P3, Canada
}

\begin{abstract}
Synopsis Electron scattering from cadmium atoms has been investigated theoretically using the Convergent Close-Coupling (CCC), Relativistic Optical Potential (ROP) and Relativistic Distorted Wave (RDW) methods. Differential, integrated and ionization cross sections have been calculated between 1 and $500 \mathrm{eV}$ and compared against experimental data. Electron impact coherence parameters have also been calculated and compared against available experiment.
\end{abstract}

The CCC, ROP and RDW methods have been very successful in the description of electron scattering from atoms and ions. Here we apply these methods to the calculation of electron scattering from the ground state of $\mathrm{Cd}\left(5^{1} \mathrm{~S}_{0}\right)$.

In the CCC method [1], the $\mathrm{Cd}$ atom is modelled as two active electrons above a closed Hartree-Fock core. The Hamiltonian of the $\mathrm{Cd}^{+}$ ion is diagonalized in a large Sturmian (Laguerre) basis. The resulting one-electron orbitals are used in a two-electron configuration-interaction calculation to obtain a set of Cd target states. A total of 183 states are used to expand the total wavefunction of the e-Cd scattering system and formulate a set of coupled Lippman-Schwinger equations for the T-matrix.

The ROP method of Chen et al [2] for elastic scattering uses an optical potential consisting of a static, polarization and imaginary absorption potential which accounts for loss of incident electron flux into the excited and ionization channels. The RDW method as applied to the excitation of Cd has been described in Srivastava et al [3]. We have used this method to calculate the excitation of the $5 s$ valence electron to the $5 p, 5 d$ and $6 s$ levels.

The CCC method has been executed for energies up to $500 \mathrm{eV}$. Electron impact coherence parameters have been calculated for the excitation of the $5^{1} \mathrm{P}_{1}$ state. As an example, we present in Figure 1 the $\mathrm{P}_{3}$ Stokes parameter for excitation at $80 \mathrm{eV}$.

Furthermore, differential cross sections have been calculated for elastic scattering and excitation of the $5^{3} \mathrm{P}_{1}, 5^{3} \mathrm{P}_{2}, 5^{1} \mathrm{P}_{1}, 6^{3} \mathrm{~S}_{1}, 6^{1} \mathrm{~S}_{0}, 5^{1} \mathrm{D}_{2}$, $6^{1} \mathrm{P}_{1}, \quad 7^{1} \mathrm{~S}_{0}, \quad 6^{1} \mathrm{D}_{2}, 7^{1} \mathrm{P}_{1}, 8^{1} \mathrm{~S}_{0}, 7^{1} \mathrm{D}_{2}$ and $8^{1} \mathrm{P}_{1}$ states. Results have been compared with the ex-

\footnotetext{
${ }^{1}$ E-mail: m.berrington@curtin.edu.au
}

perimental data of Marinković et al [4] and will be presented at the conference.

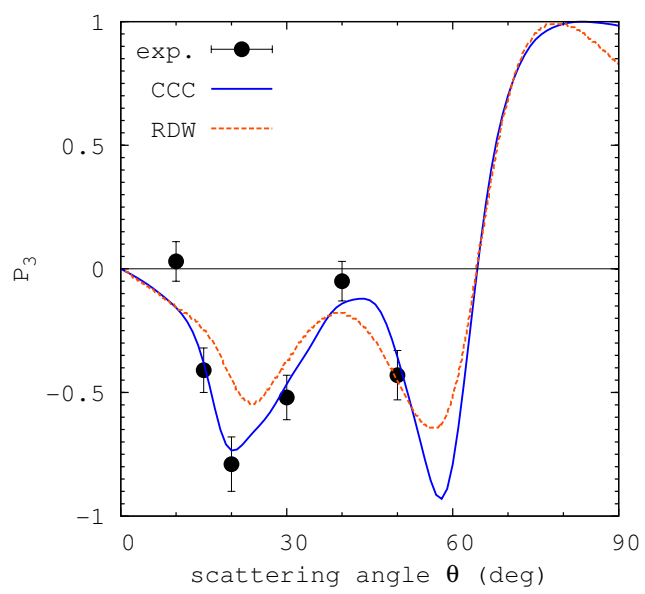

Figure 1. Stokes parameter $\mathrm{P}_{3}$ for excitation of the $5^{1} \mathrm{P}_{1}$ state of cadmium by $80 \mathrm{eV}$ electrons. Experimental data is due to Piwiński et al [5]. The theoretical RDW results are those presented in Srivastava et al [3].

\section{References}

[1] Fursa D V and Bray I 1997 J. Phys. B 305895

[2] Chen S, McEachran R P and Stauffer A D 2008 J. Phys. B 41025201

[3] Srivastava R, Zuo T, McEachran R P and Stauffer A D 1992 J. Phys. B 251073

[4] Marinković B, Pejčev V, Filipović D and Vusković L 1991 J. Phys. B 241817

[5] Piwiński M, Dziczek D, Klosowski L, Srivastava R and Chwirot R 2006 J. Phys. B 391945 